\title{
Role of fasting gastrointestinal motility in the variability of gastrointestinal transit time assessed by hydrogen breath test
}

\author{
C Di Lorenzo, C P Dooley, J E Valenzuela
}

\begin{abstract}
Gastrointestinal motility and transit time, measured by the hydrogen breath test, were simultaneously assessed in six healthy volunteers. Each subject underwent six studies on separate days. On each day motility was measured in the gastric antrum, duodenum, and proximal jejunum and $15 \mathrm{~g}$ of lactulose was given either by mouth during gastric phases I, II, III of the motor migrating complex or infused duodenally during duodenal phases $I$, II, III, one phase being studied each day in random order. Fasting activity was not interrupted by the lactulose. The lactulose transit time decreased significantly from a peak with phase I through phase II to a minimum with phase III (mean (SD) 155 (26) min $v 120$ (10) min $v 94$ (14) min, $p<0.001$ ). Similar results were noted when the lactulose was instilled intraduodenally (156 (23) $\mathrm{min} v 125$ (19) $\mathrm{min} v$ 100 (17) min, $p<0.001$ ). No correlation was found between motility index and transit. These results suggest that different phases of fasting gastrointestinal motility are major determinants of the transit time estimated by the hydrogen breath test and explain the variability of this test in practice.
\end{abstract}

Intestinal transit is an important indicator of small bowel function. Accelerated and delayed transit have been implicated in the pathogenesis of diarrhoea and constipation, respectively.' Due to the relative inaccessibility of the small intestine, measurement of intestinal transit has always been troublesome. Barium transit, ${ }^{2}$ intubation techniques, ${ }^{3}$ and scintigraphy ${ }^{4}$ have all been used in an attempt to measure intestinal transit. Less invasive and therefore more acceptable and physiologically relevant approaches are based on the presence of bacterial flora in the large intestine, although these methods only measure the transit of the leading portion of the ingested bolus. In normal subjects hydrogen is produced by bacterial breakdown of unabsorbed carbohydrates in the colon and excreted in measurable quantities in the breath. ${ }^{5}$ Raffinose and stachyose, as contained in baked beans, and sorbitol or lactulose have been used for this purpose. ${ }^{6}$ Also, the sulphasalazine/ sulphapyridine method is based on the azoreductase producing flora of the large bowel. ${ }^{\text {? }}$ Although the lactulose breath hydrogen test is now the test most widely used to measure intestinal transit time, its use is limited by excessive variability between and within subjects. How the gastric emptying influences the lactulose orocaecal transit time is not known. In this study we investigated the relation between fasting gastrointestinal motility and intestinal transit time, measured by the hydrogen breath test. The purpose of the study was to investigate in normal subjects the source of the intrasubject variability of the lactulose transit time in fasting conditions.

\section{Methods}

\section{SUBJECTS}

Studies were carried out on six male volunteers (age 27-47 years, mean 38 years). No subject gave a history of previous or present gastrointestinal illness and no medication was taken throughout the study. Each subject gave fully informed written consent for the study to be carried out and the project was approved by this institution's research committee.

\section{DESIGN OF THE STUDY}

Each subject was studied on six separate, nonconsecutive days. The subjects were intubated by mouth after an overnight fast. The motility catheter was positioned under fluoroscopic control. No sedation was used. After positioning of the catheter, the subjects were allowed one hour rest, were positioned supine, and the recording of gastrointestinal motility was started. They were allowed quiet activities and were allowed to sleep. They were instructed not to smoke, drink, or eat until the end of the study.

In each subject the three phases of the motor migrating complex (I, II, III) were visually identified. After the first motor migrating complex cycle each subject was given $15 \mathrm{~g}$ of lactulose in $10 \mathrm{ml}$ water, as a bolus, in random order, either by mouth or by intraduodenal infusion, during each of the three phases. The lactulose was given either at the beginning of phase III, or five minutes after the beginning of phase $I$ in the proximal duodenum, or 20 minutes after the beginning of phase II in the proximal duodenum. Only one phase was studied each day. Each study was performed for at least six hours or until three phase IIIs were visualised.

MEASUREMENT OF THE TRANSIT TIME BY BREATH HYDROGEN ANALYSIS

Samples of end expiratory air were obtained at the beginning of the study and at 10 minute intervals thereafter. Subjects blew into a double bag system that was filled sequentially. The first bag with a volume of $500 \mathrm{ml}$ was designed to trap the dead space. Samples were obtained from the 


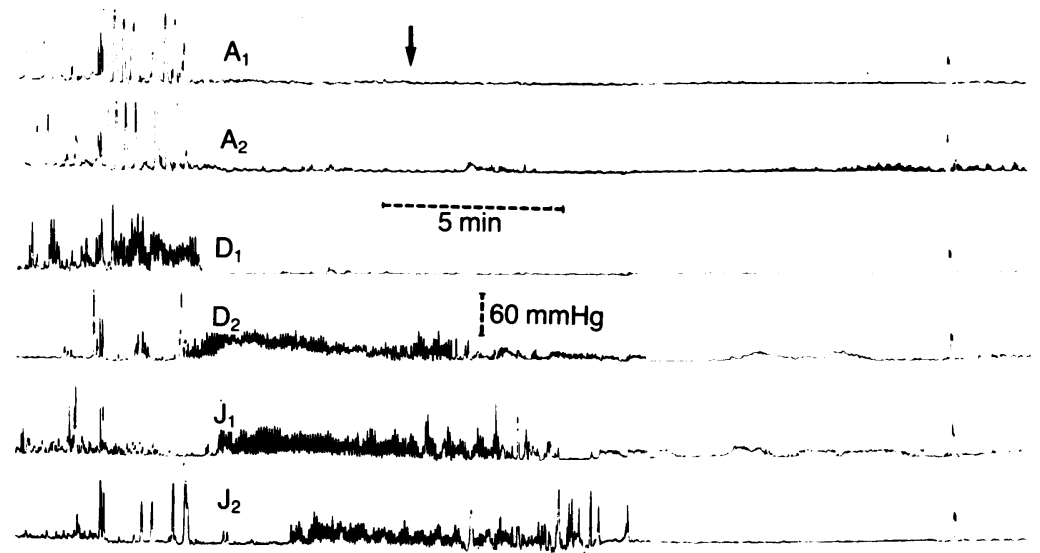

Figure 1: Motor migrating complex starting in the antrum $\left(A_{1}\right.$ and $\left.A_{2}\right)$ and migrating to the duodenum $\left(D_{1}\right.$ and $\left.D_{2}\right)$ and to the jejunum $\left(\mathcal{F}_{1}\right.$ and $\left.\mathcal{F}_{2}\right)$. The arrow indicates the ingestion of lactulose five minutes after the beginning of phase I in the proximal duodenum.

second bag, which contained alveolar air. ${ }^{8}$ Breath hydrogen concentration in ppm was determined with a Quintron microlyser (Quintron Instruments, Milwaukee, Wisconsin). The microlyser was calibrated before each experiment using a gas sample with a hydrogen concentration of $91 \mathrm{ppm}$. The transit time was taken as the time from infusion of the meal to the first sustained rise in hydrogen concentration. The latter was defined as an increase in breath hydrogen concentration of at least $10 \mathrm{ppm}$ above basal values, sustained for at least three consecutive 10 minute readings.

MEASUREMENT OF GASTROINTESTINAL MOTILITY Gastrointestinal manometry was performed with a six lumen manometric assembly placed with two recording sites in the antrum, two in the duodenum, and two in the jejunum. The distance of the side holes from the tip of the catheter was: $0,15,30,40,50$, and $52 \mathrm{~cm}$; an additional tube ending at $41 \mathrm{~cm}$ from the tip of the motility catheter was added to infuse lactulose intra-

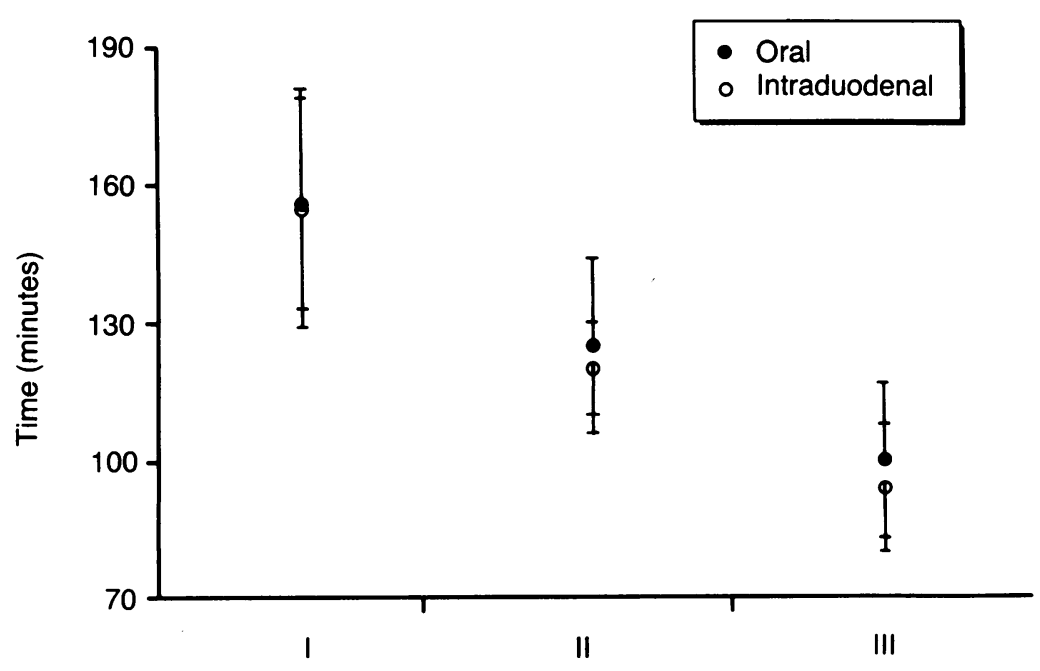

Phase of the motor migrating complex

Figure 2: Relation between transit time and phase of the motor migrating complex when lactulose was given orally (O) or infused intraduodenally (O). Each point is the mean of the values observed in the six subjects investigated. duodenally. The catheters were continuously perfused with gas free water by a low compliance pneumohydraulic infusion pump (Arndorfer Medical Specialties, Greendale, Wisconsin) at a rate of $0.5 \mathrm{ml} / \mathrm{min}$. Resistance to infusion within the system was detected by a series of external Statham P23DB transducers (Statham, Oxnard, California) positioned at the intersection of the costal margin and mid-axillary line of the subject. Sudden occlusion of each orifice resulted in a pressure rise in excess of $300 \mathrm{~mm} \mathrm{Hg} / \mathrm{s}$. Pressure profiles were displayed on a multichannel polygraph recorder (Beckman R611, Instruments, Fullerton, California).

\section{ANALYSIS OF MANOMETRIC DATA}

Individual tracings were coded and analysed in a blind fashion. The different phases of the motor migrating complex were identified and a motility index (amplitude $\times$ number of contractions) in phase II for each 15 minute period was calculated at each recording site. ${ }^{9}$ The values at the two antral, two duodenal, and two jejunal ports were averaged to obtain single antral, duodenal, and jejunal motility indices for each phase II in each subject. The length of the motor migrating complex was calculated as the time between two phase IIIs at the same recording site. The velocity of propagation of phase III was assessed by dividing the distance traversed by the activity front by the time taken to pass from the most proximal duodenal site recording the phase III to the most distal jejunal site.

\section{STATISTICAL ANALYSIS}

Results in the text and figures are expressed as means (SD). The significance of the results was assessed by analysis of variance, paired $t$ test, and regression analysis as appropriate. The coefficient of variation of the intestinal transit was calculated in each subject taking into account all six measurements performed in each subject.

\section{Results}

The infusion of lactulose either taken by mouth or infused intraduodenally did not interrupt fasting motor activity. The motor migrating complex cycling time was not significantly changed (159 (49) $\mathrm{min}$ in basal conditions $v 171$ (54) min after lactulose, not significant) and we found no qualitative changes in the upper gastrointestinal tract motility after lactulose administration. The lactulose never induced a fed pattern (Fig 1).

As the Table shows, in each subject the transit time had a high coefficient of variation when lactulose was given during different phases of the motor migrating complex. The mean coefficient of variation in the same subject was $22 \cdot 7(9 \cdot 8) \%$. The phase during ingestion of lactulose was a significant determinant of the transit time: when lactulose was given by mouth the transit time decreased significantly from a peak with phase I through phase II to a minimum with phase III (155 (26) v 120 (10) v 94 (14) min, $\mathrm{p}<0.001$ ). Similar results were noted when the lactulose 
Transit time (minutes) and coefficient of variation in the six subjects

\begin{tabular}{|c|c|c|c|c|c|c|c|}
\hline \multirow{3}{*}{$\begin{array}{l}\text { Subject } \\
\text { No }\end{array}$} & \multicolumn{6}{|l|}{ Lactulose } & \multirow{3}{*}{$\begin{array}{l}\text { Coefficien } \\
\text { of } \\
\text { variation } \\
(\%)\end{array}$} \\
\hline & \multicolumn{3}{|l|}{ By mouth } & \multicolumn{3}{|c|}{ Intraduodenally } & \\
\hline & $I$ & $I I$ & $I I I$ & $I$ & $I I$ & $I I I$ & \\
\hline $\begin{array}{l}1 \\
2 \\
3 \\
4 \\
5 \\
6 \\
\text { Mean (SD) }\end{array}$ & $\begin{array}{l}205 \\
160 \\
155 \\
140 \\
140 \\
130 \\
155(26)\end{array}$ & $\begin{array}{l}120 \\
115 \\
105 \\
135 \\
115 \\
130 \\
120(10)\end{array}$ & $\begin{array}{l}100 \\
70 \\
85 \\
110 \\
95 \\
105 \\
94(14)\end{array}$ & $\begin{array}{l}185 \\
175 \\
165 \\
150 \\
145 \\
120 \\
156(23)\end{array}$ & $\begin{array}{l}155 \\
120 \\
115 \\
145 \\
115 \\
105 \\
125(19)\end{array}$ & $\begin{array}{l}110 \\
90 \\
75 \\
105 \\
95 \\
120 \\
100(17)\end{array}$ & $\begin{array}{l}29 \\
33 \\
38 \\
18 \\
21 \\
8 \\
22(10)\end{array}$ \\
\hline
\end{tabular}

was infused intraduodenally (156 (23) $v 125$ (19) $v 100(17) \mathrm{min}, \mathrm{p}<0.001)$. For each phase the results were similar for oral intake and duodenal infusion (Fig 2).

No correlation was found between the total length of the motor migrating complex or the length of any of the phases during which lactulose was administered and transit time. No correlation was found between the motility index at any of the areas of the gastrointestinal tract evaluated and transit time ( $r$ ranging between 0.24 and 0.49 , not significant).

The range of the velocity of propagation of phase II was $17 \cdot 4-6 \cdot 1 \mathrm{~cm} / \mathrm{min}$ among the different subjects. There was no correlation between velocity of propagation of the activity front and transit time $(r=0 \cdot 42, p=$ not significant $)$.

\section{Discussion}

In this study we simultaneously evaluated intestinal transit time and gastrointestinal motility. We found that the phase of the motor migrating complex during ingestion of lactulose is the most important determinant of the intestinal transit time and it is likely to account for the variability of the hydrogen breath test in fasting conditions. We also found that in normal subjects gastric emptying is not an important factor in determining lactulose orocaecal transit time.

The hydrogen breath test has been widely used as a non-invasive and simple method of determining small bowel transit time. The validity of this test for determining orocaecal transit time has been established using the intubation technique, ${ }^{5}$ scintigraphic methods, ${ }^{4}$ radioopaque plastic markers, ${ }^{10}$ or barium meal. ${ }^{11}$ It has been used to measure the intestinal transit time in a variety of physiological conditions $\mathrm{s}^{12-15}$ and to study the effect of drugs ${ }^{1617}$ or diseases ${ }^{18} 19$ on the orocaecal transit time. The use of the breath hydrogen test for measuring orocaecal transit time therefore seems to be an intriguing research tool, although with limited clinical impact at the moment. ${ }^{20}$

A problem which has puzzled many investigators and has contributed to the limited use in clinical practice of this test is its high intra and intersubject variability. Its reproducibility has been questioned by several investigators. Good reproducibility was reported by Bond and Levitt, ${ }^{5}$ who first described the use of the lactulose hydrogen test to measure orocaecal transit time. Others have found higher coefficients of variation ranging between $18.5 \%$ and $29.7 \%$ in healthy volunteers ${ }^{12}$ and even a lower reproducibility in constipated patients with prolonged orocaecal transit. ${ }^{21}$ Our results are in the same range of those reported by investigators who used similar doses of lactulose. The dose is an important variable to be considered when using the hydrogen breath test since it has been shown that there is an inverse relation between transit time and the amount of lactulose given. This is thought to be due to the osmotic effect of the lactulose causing water retention in the lumen of the small bowel with stimulation of peristalsis. ${ }^{22}$ We used $15 \mathrm{~g}$ as study dose, the amount used in most of the previous reports, and this dose caused no qualitative changes in the manometric patterns recorded in our patients.

Reasons for the poor reproducibility of the lactulose hydrogen test may include the effect of nausea, which may be caused by ingestion of large quantities of sugar, ${ }^{23}$ the presence of different colonic flora, and the presence of the interdigestive motor activity in fasting conditions. ${ }^{12}$ In this study, for the first time, we have shown that the lactulose intestinal transit in fasting conditions in influenced by the different phases of the motor migrating complex. In an attempt to make the breath test more reproducible different investigators have suggested the inclusion of a liquid ${ }^{12}$ or semisolid ${ }^{24}$ meal. The meal changes motility from the fasting pattern characterised by the three phases of the motor migrating complex, during which transit varies considerably, to a fed pattern characterised by a less variable series of random segmental contractions. Indeed, studies which have investigated intestinal transit in fed conditions have shown a coefficient of variation of less than $10 \% .{ }^{23}$ Unfortunately, this method cannot be applied to patients who cannot tolerate oral feeding, such as some of those with chronic intestinal pseudoobstruction or severe gastrointestinal diabetic neuropathy.

It was not surprising to find no correlation between the motility index and the transit time since the same lack of correlation has been found by other investigators in fed conditions. ${ }^{25}$ Postprandially, phasic pressure events reflect mixing, retropulsion, and propulsion, and it seems likely that coordination more than frequency and amplitude of contractions plays a part in determining the intestinal transit time.

The contribution of gastric emptying to mouth to caecum transit time is largely unknown. We found that there was no difference between orocaecal and duodenocaecal transit time. This can easily be explained by considering that a liquid meal enters the duodenum within minutes of its ingestion. A previous study has shown that the two transit times differed by about one hour. ${ }^{26}$ In that study lactulose was given dissolved in $100 \mathrm{ml}$ of an elemental diet and the different methodology could at least in part be responsible for the discrepancy with our results. It is possible that in another group of subjects, such as patients with gastroparesis, gastric emptying would contribute more to the total transit time. It has also been reported that there is no correlation between lactulose transit time and its gastric emptying, ${ }^{6}$ suggesting different control mechanisms for the two functions. Read et al have recently perfected a method of 
quantifying each element of total gut transit by adding radio-opaque markers to a standard meal for faecal recovery and labelling the meal with $99 \mathrm{~m}$-technetium to allow determination of gastric emptying. ${ }^{22}$

The use of the hydrogen breath test in fasting conditions is limited by its intrasubject variability. This is due to the different phases of the motor migrating complex occurring in the upper gastrointestinal tract when lactulose is ingested. Further studies are needed to determine whether the higher reproducibility found when lactulose is given with or after a meal is due to the induction of a fed pattern.

We acknowledge the excellent technical assistance provided by Charito Ocampo and George Franklin.

1 Cann PA, Read NW, Brown C, Hobson N, Holdsworth CD. Irritable bowel syndrome: relationship of disorders in the transit of a single solid meal to symptoms patterns. Gut 1983 24: 405-11.

$2 \mathrm{Kim}$ SK. Small intestine transit time in the normal bowe study. $A \mathcal{F R} 1$ 1968; 104: 522-4.

3 Read NW, Al Janabi MN, Bates TE, Barber DC. Effect of gastrointestinal intubation on the passage of a solid meal gastrointestinal intubation on the passage of a solid meal
through the stomach and small intestine in humans. Gastrothrough the stomach and small

4 Caride VJ, Prokop IK, Troucale FJ, Buddoura W, Winchenbach K, McCallum RW. Scintigraphic determination of small intestinal transit time: comparison with the hydrogen breath technique. Gastroenterology 1984; 86: 714 20.

5 Bond JH, Levitt MD. Investigation of small bowel transit time in man utilizing pulmonary hydrogen $\left(\mathrm{H}_{2}\right)$ measurements. f L ab Clin Med 1975; 85: 546-55.

6 Read NW, Miles CA, Fisher D, Holgate AM, Kime ND, Mitchell MA et al. Transit of a meal through the stomach, mall intestine and coln in normal through the stomach, the pathogenesis of diarrhea. Gastroenterology 1980; 79: the pathog

7 Kennedy M, Chinwah P, Wade DN. A pharmacological method of measuring mouth caecal transit time in man. method of measuring mouth caecal

8 Metz G, Gassull Ma, Leeds AR, Blendis LM, Jenkis DJA. A simple method of measuring breath hydrogen in carbo hydrate malabsorption by end expiratory sampling. Clin $\mathrm{Sc}$ Mol Med 1976; 50: 237-40.

9 Kellow JE, Borody TJ, Phillips SF, Tucker RL, Haddad AC. Human interdigestive motility: variation in patterns from the esophagus to colon. Gastroenterology 1986; 91: 386-95.
10 Armbrecht U, Jansen J, Eden S, Stockbrugger R. Assessment of orocecal transit time by means of hydrogen $\left(\mathbf{H}_{2}\right)$ breath test as compared with a radiological control method. Scand $\mathcal{F}$ Gastroenterol 1986; 21: 669-77.

11 Hirokawa $M$, Iida $M$, Kohrogi N, Fujishima $M$. Hydrogen breath test assessment of orocecal transit time: comparison with barium meal study. Am $\mathcal{F}$ Gastroenterol 1988; 83: 1361-3.

12 La Brooy SJ, Male PJ, Beavis AK, Misiewicz JJ. Assessment of the reproducibility of the lactulose $\mathrm{H}_{2}$ breath test as a of the reproducibility of the lactulose $\mathrm{H}_{2}$ breath test as a measur.

13 Wald A, Van Thiel DH, Hoechstetter L, Gavaler JS, Egler $\mathrm{KM}$, Verm R, et al. Gastrointestinal transit: the effect of menstrual cycle. Gastroenterology 1981; 80: 1495-500.

14 Lawson M, Kern F Jr, Everson GT. Gastrointestinal transit time in the second and third trimesters followed by postpartum normalization. Gastroenterology 1985; 89: 996-9.

15 Meshkimpour H, Kemp C, Fairshter R. Effect of aerobic exercise on mouth-to-caecum transit time. Gastroenterology 1989; 96: 938-41.

16 Rubinoff MJ, Piccione PR, Holt PR. Clonidine prolongs small intestine transit time: use of the lactulose-breath hydrogen intestine transit time: use of the lactulose-

17 Van Wyk M, De Sommers K, Steyn AGW. Evaluation of gastrointestinal motility using the hydrogen breath test. Brf Pharmacol 1985; 20 : 479-81.

18 Shafer RB, Prentiss RA, Bond JH. Gastrointestinal transit in thyroid disease. Gastroenterology 1984; 86: 852-5.

9 Scarpello JHB, Greaves M, Sladen GE. Small intestinal transit in diabetes. $B M F$ 1976; $2: 1225-6$.

20 Gilmore IT. Orocaecal transit time in health and disease. Gut 1990 ; 31: 250-1.

21 Camboni G, Basilisco G, Bozzani A, Bianchi PA. Repeatability of lactulose hydrogen breath test in subjects with normal or prolonged orocecal transit. Dig Dis Sci 1988; 33: 1525-7.

22 prolonged orocecal transit. Dig Dis Sci dose and osmolality of lactulose on the oral-caecal transit time determined by the hydrogen breath test and the reproducibility of the test in hydrogen breath test and the reproducibility of

23 Ladas SD, Latoufis C, Giannopoulou H, Hatziioannou J, Raptis SA. Reproducible lactulose hydrogen breath test as a measure of mouth to caecum transit time. Dig Dis Sci 1989; 34: $919-24$

24 Staniforth DH, Rose D. Statistical analysis of the lactulose/ breath test in the measurement of orocaecal transit: its variability and predictive values in assessing drug action. Gut 1989; 30: 171-5.

25 Read NW, Al-Janabi MN, Edwards CA, Barber DC. Relationship between postprandial motor activity in the human small ship between postprandial motor activity in the human small intestine and the gastrointes

26 Korth H, Muller I, Erckenbrecht, Wiembeck M. Breath hydrogen as a test for gastrointestinal transit. Hepatogastroenterology 1984; 31:282-4.

27 Read NW, Miles CA, Fisher D, Holgate AM, Kime ND, Mitchell MA, et al. Transit of a meal through the stomach, small intestine, and colon in normal subjects and its role in the pathogenesis of diarrhea. Gastroenterology 1980; 79: 1276-82. 